\title{
APPLICATION OF CARBON NANOTUBES FOR CONTROLLED RELEASE OF GROWTH FACTORS OR ENDOCANNABINOIDS: A BREAKTHROUGH IN BIOMEDICINE
}

\author{
Parichehr Hassanzadeh, Fatemeh Atyabi, and Rassoul Dinarvand \\ Nanotechnology Research Center, Faculty of Pharmacy, Tehran University of Medical Sciences, \\ Tehran, Iran
}

Carbon nanotubes (CNTS), the nanostructures with immense potential in various scientific fields such as the regenerative medicine, have emerged as innovative nanosreservoirs with multimodal functionality and application in theranostic settings. The superior mechanical properties, high thermoelectrical conductivities, or improved solubility and biocompatibility have made CNTs as suitable candidates for biosensing, high-resolution imaging, tissue engineering, and delivery of a variety of compounds with poor solubility or short half-life. These advanced nanovectors which promote neuronal growth and functional connectivity, have shown great theranostic potential in the central nervous system disorders. Several pioneering works have shown the ability of CNTs for controlled release of drugs or growth factors into the brain. Over the last decade, the neurotrophic and metabotrophic effects of nerve growth factor, brain-derived neurotrophic factor and endocannabinoid system and their involvement in the mechanism of action of a wide variety of drugs have been the focus of intense research. In order to overcome the rapid degradation and/or non-specific distribution of nerve growth factor or endocannabinoids, conjugation with CNTs has led to the prolonged effects of these modulating factors. Based on their unique properties, the appropriate application of functionalized CNTs may indeed revolutionize the current biomedical interventions that has been highlighted in the present review. Biomed Rev 2016; 27: 41-49

Key words: nanotechnology, advanced nanovectors, theranostic settings

\section{INTRODUCTION}

Treatment of neurological disorders has remained as one of the most challenging areas of medicine. Traumatic injuries to the central nervous system (CNS) including the spinal cord injury (SCI) and traumatic brain injury (TBI) may lead to the progressive or irreversible damages. The currently avail- able drugs do not reverse the condition and the neurosurgical approaches are usually associated with various complications and remarkable costs. Furthermore, application of the artificial transplants or transplanted organs necessitates the lifelong immunosuppression (1). During the last few decades, nanotechnology has emerged as a rapidly developing interdis-

Received 28 November 2016, accepted 7 December 2016.

Correspondence to: Dr Parichehr Hassanzadeh, Nanotechnology Research Center, Faculty of Pharmacy, Tehran University of Medical Sciences, Tehran, Iran Tel/Fax: +98 21 66959052, Cell phone: +98 9121887745

E-mail: p-hassanzadeh@razi.tums.ac.ir 
ciplinary approach with a vast discovery area in the basic or clinical research. Indeed, application of this highly advanced technology has expanded our knowledge about the molecular mechanisms of the neurological disorders. The highly efficient nanotech-based vehicles have been designed to transport a wide variety of molecules across the blood-brain barrier (BBB) (2) which prevents the entrance of large molecules or hydrophilic drugs into the brain (3). Among the precisely engineered nanomaterials, carbon nanotubes (CNTs) have emerged as the innovative nanostructures with multimodal functionality and application in theranostic settings. CNTs with high surface reactivity, electrothermal conductivity, biocompatibility, and intrinsic diagnostic capability have been successfully used for biosensing, high-resolution and non-invasive imaging, tissue engineering, and efficient delivery of drugs or biomolecules (4-6). Moreover, CNT-neurotrophin conjugates are able to promote neurite outgrowth and connectivity of neuronal networks $(3,5)$.

In recent years, neurotrophic and metabotrophic effects of nerve growth factor (NGF), brain-derived neurotrophic factor (BDNF) and endocannabinoid system (eCBs) and their involvement in the pathogenesis and therapy of neurodegenerative and cardiometabolic diseases have been the focus of intense research (7-13). Meanwhile, rapid degradation, poor solubility, or non-specific distribution of NGF or endocannabinoids $(14,15)$ may negatively affect their effectiveness that necessitates the development of suitable carriers to provide longer lasting effects for these modulators. In this respect, application of CNTs has shown promising results that will be discussed herein.

\section{CARBON NANOTUBES: THE GENERAL ASPECTS}

The strongest materials yet discovered, CNTs are categorized as single- and multi-walled CNTs (SWCNTs and MWCNTs, respectively). Unlike their tiny diameters, the length of CNTs may be extended to hundreds of micrometers. Such an extraordinary length-to-diameter ratio may result in a precise detection of biological or chemical compounds and high drug loading (16). Because of their small size, CNTs may be easily distributed and react with living cells (17). Due to the highly reactive surface, CNTs bind to a wide variety of molecules including the drugs, genes, proteins, and markers (18) that might be of great theranostic significance. In the neuronal tissue or muscles, CNTs have been used as stimulants or sensors (19). CNTs may also be used as the glucose sensors because of their ability to control far-infrared luminescence (20) and suppress the bacterial proliferation (21) that might be useful in infectious diseases. At initial stages in cancers, CNTs are able to detect the expression of biomarkers and inhibit tumour growth by enhancement of permeability and retention of anticancer agent (22). CNT composites with high drug encapsulation efficiency have been used for prolonged drug release (23). Interestingly, real-time monitoring of drug delivery is possible due to the intrinsic spectroscopic properties of CNTs (24).

Regarding the potential toxicity of CNTs, inflammatory reactions may occur in the case of structural defects of CNTs. Meanwhile, these reactions are usually mild and short-lasting as CNTs are rapidly eliminated from the body due to their small size (25). In general, the efficiency and adverse effects of CNTs, like other nanomaterials, depend on their mode of application. In a 2-year bioassay, MWCNTs have shown no carcinogenicity (26). Regarding the cortical neurons, pluroniccoated CNTs not only did not induce degeneration in vitro or in vivo, but also reduced pluronic toxicity (27). In the clinical settings, carbon-based biomaterials have been used for a long time without serious adverse reaction (28). In general, surface modification of CNTs make them more soluble, bioactive, and biocompatible leading to the reduced cytotoxicity of these nanostructures (29).

\section{APPLICATION OF CARBON NANOTUBES IN REGENERATIVE MEDICINE: THE FOCUS ON NEUROLOGICAL DISORDERS}

The limited efficacy of the current treatment strategies against the neurodegenerative disorders may adversely affect patient's compliance and quality of life. For instance, silicon implants in the cerebral cortex or neuroprosthetics may be surrounded by astroglial scars leading to a significantly reduced efficiency of electrical stimulation (30). Furthermore, polymer-based nerve growth conduits may be associated with limitations due to their low biocompatibility or unfavourable physicochemical properties (31). These problems have evoked tremendous efforts towards the development of novel therapeutic approaches to improve neural repair or motor functional recovery. In this respect, application of CNTs in regenerative medicine has attracted a growing interest. Development of the CNT-based devices has led to the regeneration of damaged neurons or facilitation of drug delivery across the BBB. Because of their high biocompatiblility and electroconductivity, CNT-based scaffolds are able to induce the regeneration of Schwann cells, differentiation of embryonic stem cells into the neurons, and improve neuronal performance (32- 34). In this context, interfacing the hippocampal neurons with CNTs has led to 
the strong potentiation of spontaneous synaptic activity. Furthermore, culturing of cortical neurons on CNT clusters resulted in the formation of a well-organized neural network (35) suggesting the suitability of CNTs for neural applications. Interestingly, the interaction between neurons and CNTs may lead to the activation of intracellular signalling cascades. For instance, CNTs-induced neurite outgrowth is associated with the activation of extracellular signal-regulated kinase and phospholipase C signalling pathways, respectively (36).

The ability of CNTs to modulate the electrochemical events in the neural networks has represented them as the attractive nanodevices for neuromodualtion. In Alzheimer's disease which is the most common cause of severe memory problems in the elderly, the currently available treatments have shown limited efficacy. Because of the cholinergic deficit, the suitable treatment options should increase the cholinergic neurotransmission (37). Since acetylcholine has a short half-life and does not readily cross the $\mathrm{BBB}(37)$, CNTs may be used as the carriers of acetylcholine. In an experimental model of Alzheimer's disease, acetylcholine-loaded SWCNTs have restored the cognitive function, while, free acetylcholine showed no effect (38). MWCNTs have been used as the high-resolution probes for visualizing the amyloid- $\beta$ (A $\beta$ ) fibrils (39). Furthermore, CNT-based biosensors provide the possibility for real-time detection of $\mathrm{A} \beta$ in human serum with lower limit of detection as compared to the enzyme-linked immune sorbent assay (40).

In Parkinson's disease, one of the most common neurodegenerative disorders worldwide, the currently available drugs alleviate the symptoms but do not affect disease progression (41). Furthermore, infusion pumps or skin patches may be associated with various complications (42). Since the conventional techniques for deep brain stimulation (DBS) are usually associated with multiple limitations such as high electrical current needs, large size of electrodes, and lack of feedback monitoring of brain electrical activity (43), CNTs might be attractive nanomaterials for DBS due to their prolonged stability and ability for real time neuromonitoring, neuromodulation, and large charge storage (44).

In multiple sclerosis (MS), a debilitating autoimmune disease of CNS which is associated with myelin degradation and cognitive impairment, disease modifying agents including the immunosuppressants, monoclonal antibodies, or high-dose corticosteroids do not stop the disease process (45). Because of their ability to record or stimulate the neural activity, CNTs might be promising theranostic candidates in MS. In this respect, CNT-neuron hybrid networks have been shown to improve the neuronal network connectivity and performance (46). In epilepsy, one of the most prevalent neurological disorders which is associated with abnormal electrical activity within the brain, the conventional antiepileptic drugs are usually associated with various side effects and do not effectively reduce the seizure severity or frequency (47). CNTs due to their unique properties have been represented as suitable carriers for drug delivery into the brain (48).

Following SCI, permanent paralysis occurs because of the inability of axons to regenerate across the lesion. Application of neuroprotective agents or stem cell therapy does not usually result in a functional repair $(49,50)$, while, post-SCI administration of SWNT-polyethylene glycol has promoted tissue repair in the experimental SCI (51). In brain injuries, transplantation of neural stem cells into the injured region may be associated with multiple limitations because of their low survival rate (52). CNTs as biocompatible substrates or scaffolds by promoting the differentiation and maturity of neural stem cells provide improved function of damaged nerve tissues (53). Application of CNTs have been shown to reduce the levels of inflammatory markers and promote the recovery from stroke $(54,55)$. Moreover, CNT-mediated siRNA delivery and gene silencing of neuronal tissues has successfully promoted functional motor recovery from brain ischemic insult (56).

\section{CONJUGATION OF CARBON NANOTUBES WITH GROWTH FACTORS OR ENDOCANNABINOIDS: IMPROVED TREATMENT OUTCOMES}

Growth factors, the endogenous polypeptides which regulate the cellular proliferation, migration and differentiation, have been presented as leading therapeutic candidates in neural tissue engineering (57). Because of the rapid degradation or non-specific distribution after systemic administration, the outcome of growth factor-based therapies largely depends on their delivery mode. In this respect, advanced growth factor delivery systems have been designed among which the functionalized CNTs proved to be particularly promising for controlled release of growth factors (58). For targeted killing of cancer cells, epidermal growth factor-directed CNT-drug conjugates have shown efficiency both in vitro and in vivo (59).

Carbon nanotubes loaded with GDNF, a glial cell linederived neurotrophic factor for midbrain dopaminergic neurons, increase the integration of transplanted embryonic dopaminergic neurons into the striatum and promote neuronal survival (60). Indeed, the promotion of neurite outgrowth and synaptogenesis by neurotrophin-coated CNTs has attracted a 
growing interest (61). The prototypic member of the neurotrophin family, nerve growth factor (NGF), which plays a regulatory role in the survival, differentiation, and maintenance of the functions of specific populations of neurons and mediates the therapeutic effects of a wide variety of CNS drugs (8-13), is trophic for the cholinergic neurons which are critically involved in the cognitive processes (62). NGF has also shown therapeutic potential in the neurological disorders such as SCI and Alzheimer's disease $(63,64)$. In dorsal root ganglia or PC12 cells, CNTs-NGF complex is able to promote the neuronal outgrowth $(65,66)$. In an in vitro model of ischemic stroke, aminated MWCNTs have been presented as efficient nanocarriers for NGF which provide a sustained concentration and longer lasting effects for this neurotrophin (67) that might be of therapeutic significance against the disorders associated with NGF deficiency. In the latter study, MWCNTs-NGF complex dose-dependently attenuated the oxidative stress via the reduction of MDA; a marker of lipid peroxidation, tissue injury, and free radical generation (68), and elevation of the activities of antioxidant enzymes including the SOD; an enzyme which is implicated in the cell protection against the oxidative damage, and CAT; the scavenger of hydrogen peroxide which is a cell-permeable oxidizing agent (69). Since the neurotrophic factors promote the expression of antioxidant proteins and the loss of neurotrophic support may lead to the development of various disorders in the central or peripheral nervous system $(14,57)$, therefore, prolonged suppression of oxidative stress by CNTs-NGF complex might be of great therapeutic value against the neurological disorders.

Based on the protective effects of NGF against the cerebral insults and forebrain ischemia (70), the ability of CNTs to provide a sustained concentration and longer lasting effects for NGF may be beneficial against the cellular dysfunction due to the acute or chronic form of neural injury. Interestingly, both NGF and CNTs modulate the synaptic plasticity (5, 8-13, 27), therefore, application of NGF-CNTs complex appears as a promising treatment option against the disorders which are associated with abnormal synaptic plasticity.

According to a recently published report, functionalized CNTs prolong the regulatory action of NGF on the endocannabinoid system (eCBs) (71). It has been shown that CNTs-NGF complex induces a long-lasting enhancement of brain 2-arachidonoylglycerol (2-AG) content indicating the efficiency of this nanostructure to provide a sustained concentration of NGF. Furthermore, the implication of 2-AG in the mechanism of action of NGF has been demonstrated
(71) that might be of great therapeutic significance in the neurological disorders. Indeed, identification of the eCBs (a group of neuromodulatory lipids and their receptors) which is implicated in a wide variety of physiological and pathological processes (72), has provided new insights into the mechanisms underlying the pathophysiology of various diseases that may result in the development of novel treatment strategies. The endocannabinoids, anandamide and $2-\mathrm{AG}$, are produced ondemand from the membrane lipid precursors and release from postsynaptic neurons. They are ligands of two types of $G$ protein-coupled receptors, cannabinoid $\mathrm{CB}_{1}$ and $\mathrm{CB}_{2}$, which are predominantly located in the central nervous system and immune cells, respectively (73). In the mammalian brain, $\mathrm{CB}_{1}$ receptors are highly expressed in the areas which control emotional, cognitive, sensory and motor functions. Endocannabinoids by the activation of presynaptic $\mathrm{CB}_{1}$ receptors act as retrograde synaptic messengers and inhibit the release of the excitatory and inhibitory neurotransmitters (74). Following different types of diseases, enhancement of the activity of eCBs may result in the therapeutic effects. In this sense, development of the cannabinoid receptor agonists, anandamide uptake blockers, or selective inhibitors of endocannabinoid degradation, has triggered increasing research efforts $(75,76)$. Based on the involvement of eCBs in the survival signaling pathways and neural plasticity and its modulatory effects on the neurodegenerative and neuroinflammatory processes (72-74), malfunctioning of the eCBs may contribute to the etiology of neurological disorders. In this context, pharmacological manipulation of this system might be of therapeutic significance in the neurological problems as there are reports suggesting the therapeutic potential of the eCBs in multiple sclerosis, stroke, Alzheimer's disease, spinal cord injury, and epilepsy (77-81).

In an in vitro model of stroke, anandamide-CNTs complex has shown sustained protective effects as compared to anandamide alone which its therapeutic potential may be negatively affected by its short half-life or poor solubility (82). Aminated CNTs have been represented as suitable carriers for anandamide which provide sustained concentration for this cannabinoid leading to the longer-lasting effects against the ischemic insult induced by oxygen-glucose deprivation. Anandamide-CNTs complex by suppressing the oxidative stress and increasing the cell viability has been suggested as a valuable therapeutic agent against the ischemic stroke or other neurodegenerative pathologies (82).

Moreover, conjugation of endocannabinoids with CNTs has led to the sustained therapeutic effects in gastrointestinal 
disorders. In a rat model of colitis, 2-AG-CNTs complex has been designed in order to improve the pharmacological profile of 2-AG. This nanocomplex by providing a sustained concentration of 2-AG showed promising therapeutic effects through the anti-inflammatory and antioxidant mechanisms (83). Based on the high biocompatibility of CNTs and their ability for controlled drug delivery, anandamide-CNTs complex via the antioxidant mechanism has shown prolonged gastroprotective effects in an experimental model of gastric ulcer (unpublished data).

\section{CONCLUSION}

Implication of NGF in the molecular mechanisms of autoimmune and cardiometabolic disorders and a wide variety of psychotropic agents as well as its therapeutic potentials in neurological disorders have made this neurotrophin as an attractive candidate for theranostic settings. Meanwhile, NGF similar to other neurotrophic factors does not significantly penetrate the BBB and may be rapidly degraded. Therefore, the clinical significance of NGF depends on the development of suitable carrier systems which elevate the stability and retention of NGF in the target organ. Over the last decade, increasing research efforts have been attracted towards the eCBs which is the modulator of many cellular and physiological functions and neuroinflammatory or neurodegenerative processes. This ubiquitous signaling system may be a promising target for drug discovery particularly in disorders for which no effective therapeutic or prophylactic regimens are currently available. However, the poor solubility or short half-life may negatively affect the effectiveness of cannabinoids.

The outstanding breakthroughs in nanotechnology have provided the opportunities to develop more sophisticated delivery systems to improve the treatment outcomes. In this respect, CNTs have emerged as one of the most attractive candidates due to their outstanding properties including the biomechanical stability, capacity to integrate with neurons, re-establishment of synaptic connections, neuromonitoring, neuromodulation, and controlled drug delivery. These nanostructures have been represented as promising carriers for NGF or cannabinoids which provide longer lasting effects for these modulators that might be of great theranostic significance in a wide variety of pathological conditions including the neurological or gastrointestinal disorders. It appears that application of biofunctionalized CNTs will be considered as a major part of the next generation of therapeutic strategies in biomedicine.
Conflict of interest statement: The authors declare that the research was conducted in the absence of any commercial or financial relationships that could be construed as a potential conflict of interest.

\section{REFERENCES}

1. Bramlett HM, Dietrich WD. Progressive damage after brain and spinal cord injury: pathomechanisms and treatment strategies. Prog Brain Res 2007; 161: 125-141. DOI: 10.1016/S0079-6123(06)61009-1

2. Ricci M, Blasi P, Giovagnoli S, Rossi C. Delivering drugs to the Central Nervous System: a medicinal chemistry or a pharmaceutical technology issue? Curr Med Chem 2006; 13: 1707-1725. PMID: 16787219

3. Abbott NJ, Ronnback L, Hansson E. Astrocyte-endothelial interactions at the blood-brain barrier. Nat Rev Neurosci 2006; 7: 41-53. DOI:10.1038/nrn1824

4. Mohammadi A, Moghaddam AB, Dinarvand R, RezaeiZarchi S. Direct electron transfer of polyphenol oxidase on carbon nanotube surfaces: Application in biosensing. Int J Electrochem Sci 2009; 4: 895-905. (by ESG: www. electrochemsci.org)

5. Bosi S, Fabbro A, Ballerini L, Prato M. Carbon nanotubes: a promise for nerve tissue engineering? Nanotechnol Rev 2013; 2: 47-57. DOI: 10.1515/ntrev-2012-0067

6. Sobhani Z, Dinarvand R, Atyabi F, Ghahremani M, Adeli M. Increased paclitaxel cytotoxicity against cancer cell lines using a novel functionalized carbon nanotube. Int $J$ Nanomedicine 2011; 6: 705-719. DOI:10.2147/IJN.S17336

7. Yanev S, Aloe L, Fiore M, Chaldakov GN. Neurotrophic and metabotrophic potential of nerve growth factor and brain-derived neurotrophic factor: Linking cardiometabolic and neuropsychiatric diseases. World J Pharmacol 2013; 2: 92-99. DOI: 10.5497/wjp.v2.i4.92

8. Hassanzadeh P, Hassanzadeh A. Involvement of the neurotrophin and cannabinoid systems in the mechanisms of action of neurokinin receptor antagonists. Eur Neuropsychopharmcol 2011; 21: 905-917. doi:10.1016/j. euroneuro.2011.01.002

9. Hassanzadeh P, Rahimpour S. The cannabinergic system is implicated in the upregulation of central NGF protein by psychotropic drugs. Psychopharmacology 2011; 215: 129-141. DOI:10.1007/s00213-010-2120-4

10. Hassanzadeh P, Hassanzadeh A. Effects of different psychotropic agents on the central nerve growth factor protein. Iran J Basic Med Sci 2010; 13: 202-209. (without DOI) 
11. Hassanzadeh P, Hassanzadeh A. Implication of NGF and endocannabinoid signalling in the mechanism of action of sesamol: a multi-target natural compound with therapeutic potential. Psychopharmacology 2013; 229: 571-578. DOI:10.1007/s00213-013-3111-z

12. Hassanzadeh $\mathrm{P}$, Hassanzadeh $\mathrm{A}$. The $\mathrm{CB}_{1}$ receptor-mediated endocannabinoid signaling and NGF: The novel targets of curcumin. Neurochem Res 2012; 37: 1112-1120. DOI:10.1007/s11064-012-0716-2

13. Hassanzadeh P, Arbabi E, Atyabi F, Dinarvand R. The endocannabinoid system and NGF are involved in the mechanism of action of resveratrol: a multi-target nutraceutical with therapeutic potential in neuropsychiatric disorders. Psychopharmacology 2016; 233: 1087-1096. DOI:10.1007/s00213-015-4188-3

14. Lindsay RM. Neurotrophic growth factors and neurodegenerative diseases: therapeutic potential of the neurotrophins and ciliary neurotrophic factor. Neurobiol Aging 1994; 15: 249-251. PMID:7838303

15. Jarho P, Urtti A, Pate DW, Suhonen P, Järvinen T. Increase in aqueous solubility, stability and in vitro corneal permeability of anandamide by hydroxypropyl-ß-cyclodextrin. Int J Pharm 1996; 137: 209-216. SICI:03785173(1996)137:2<209:IIASSA>2.0.ZU;2-8

16. Liu Z, Sun X, Nakayama-Ratchford N, Dai H. Supramolecular chemistry on water-soluble carbon nanotubes for drug loading and delivery. ACS Nano 2007; 1: 50-56. DOI:10.1021/nn700040t

17. Shi Kam NW, Jessop TC, Wender PA, Dai H. Nanotube molecular transporters: internalization of carbon nanotube-protein conjugates into mammalian cells. $\mathrm{J} \mathrm{Am} \mathrm{Chem}$ Soc 2004; 126: 6850-6851. DOI:10.1021/ja0486059

18. Lacerda L, Bianco A, Prato M, Kostarelos K. Carbon nanotubes as nanomedicines: from toxicology to pharmacology. Adv Drug Deliv Rev 2006; 58: 1460-1470. DOI:10.1016/j.addr.2006.09.015

19. Saito N, Haniu H, Usui Y, Aoki K, Hara K, Takanashi $\mathrm{S}$, et al. Safe clinical use of carbon nanotubes as innovative biomaterials. Chem Rev 2014; 114: 6040-6079. DOI:10.1021/cr400341h

20. Barone PW, Baik S, Heller DA, Strano MS. Near-infrared optical sensors based on single-walled carbon nanotubes. Nat Mater 2005; 4: 86-92. DOI:10.1038/nmat1276

21. Liu S, Ng AK, Xu R, Wei J, Tan CM, Yang Y, et al. Antibacterial action of dispersed single-walled carbon nanotubes on Escherichia coli and Bacillus subtilis in- vestigated by atomic force microscopy. Nanoscale 2010; 2: 2744-2750. DOI:10.1039/c0nr00441c

22. Liu Z, Chen K, Davis C, Sherlock S, Cao Q, Chen $\mathrm{X}$. Drug delivery with carbon nanotubes for in vivo cancer treatment. Cancer Res 2008; 68: 6652-6660. DOI:10.1158/0008-5472.CAN-08-1468

23. Zhang X, Hui Z, Wan D, Huang H, Huang J, Yuan H, et al. Alginate microsphere filled with carbon nanotube as drug carrier. Int J Biol Macromol 2010; 47: 389-395. DOI:10.1016/j.ijbiomac.2010.06.003

24. Azimirad V, Hosseinpour M, Shahabi P, Alimohammadi M, Sadighi M, Hatami H. Effects of injection of carbon nanotubes on EEG and results of a behavioral test in rats. Neurophysiology 2015; 47: 198-204. doi:10.1007/s11062015-9521-2

25. Kolosnjaj J, Szwarc H, Moussa F. Toxicity studies of carbon nanotubes. Adv Exp Med Biol 2007; 620: 181-204. PMID:18217344

26. Muller J, Delos M, Panin N, Rabolli V, Huaux F, Lison D. Absence of carcinogenic response to multiwall carbon nanotubes in a 2-year bioassay in the peritoneal cavity of the rat. Toxicol Sci 2009; 110: 442-448. DOI:10.1093/ toxsci/kfp100

27. Bardi G, Tognini P, Ciofani G, Raffa V, Costa M, Pizzorusso T. Pluronic-coated carbon nanotubes do not induce degeneration of cortical neurons in vivo and in vitro. Nanomedicine: Nanotech Biol Med 2009; 5: 96-104. DOI:10.1016/j.nano.2008.06.008

28. Saito N, Haniu H, Usui Y, Aoki K, Hara K, Takanashi S, et al. Safe clinical use of carbon nanotubes as innovative biomaterials. Chem Rev 2014; 114: 6040-6079. dx.doi. org/10.1021/cr400341h

29. Ya-Ping S, Kefu F, Yi L, Weijie H. Functionalized carbon nanotubes: properties and applications. Acc Chem Res 2002; 35: 1096-1104. DOI: 10.1021/ar010160v

30. Turner JN, Shain W, Szarowski DH, Andersen M, Martins $\mathrm{S}$, Isaacson $\mathrm{M}$, et al. Cerebral astrocyte response to micromachined silicon implants. Exp Neurol 1999; 156: 33-49. DOI:10.1006/exnr.1998.6983

31. Kabanov AV, Gendelman HE. Nanomedicine in the diagnosis and therapy of neurodegenerative disorders. Prog Polym Sci 2007; 32: 1054-1082. PMID:20234846

32. Tran PA, Zhang L, Webster TJ. Carbon nanofibers and carbon nanotubes in regenerative medicine. $A d v$ Drug Deliv Rev 2009; 61: 1097-1114. DOI:10.1016/j. addr.2009.07.010 
33. Malarkey EB, Fisher KA, Bekyarova E, Liu W, Haddon RC, Parpura V. Conductive single-walled carbon nanotube substrates modulate neuronal growth. Nano Lett 2009; 9: 264-268. DOI:10.1021/n1802855c

34. Cellot G, Cilia E, Cipollone S, Rancic V, Sucapane A, Giordani $S$, et al. Carbon nanotubes might improve neuronal performance by favouring electrical shortcuts. Nat Nanotechnol 2009; 4: 126-133. DOI:10.1038/ nnano.2008.374

35. Gabay T, Jakobs E, Ben-Jacob E, Hanein Y. Engineered self-organization of neural networks using carbon nanotube clusters. Phys A: Stat Mechan Appl 2005; 350: 611-621. DOI: 10.1016/j.physa.2004.11.007

36. Matsumoto K, Shimizu N. Activation of the phospholipase $\mathrm{C}$ signaling pathway in nerve growth factor-treated neurons by carbon nanotubes. Biomaterials 2013; 34: 5988-5994. DOI:10.1016/j.biomaterials.2013.04.038

37. Masters CL, Cappai R, Barnham KJ, Villemagne VL. Molecular mechanisms for Alzheimer's disease: implications for neuroimaging and therapeutics. $J$ Neurochem 2006; 97: 1700-1725. DOI:10.1111/j.1471-4159.2006.03989.x

38. Yang Z, Zhang Y, Yang Y, Sun L, Han D, Li H, et al. Pharmacological and toxicological target organelles and safe use of single-walled carbon nanotubes as drug carriers in treating Alzheimer disease. Nanomedicine 2010; 6: 427-441. DOI:10.1016/j.nano.2009.11.007

39. Wong SS, Harper JD, Lansbury PT, Lieber CM. Carbon nanotube tips: high-resolution probes for imaging biological systems. J Am Chem Soc 1998; 120: 603-604. DOI: 10.1021/ja9737735

40. Oh J, Yooc G, Chang YW, Kim HJ, Jose J, Kim E, et al. A carbon nanotube metal semiconductor field effect transistor-based biosensor for detection of amyloid-beta in human serum. Biosensors Bioelectronics 2013; 50: 345-350. DOI:10.1016/j.bios.2013.07.004

41. Schrag A, Quinn NP, Ben-Shlomo Y. Heterogeneity of Parkinson's disease. J Neurol Neurosurg Psychiatry 2006; 77: 275-276. PMID:16421140

42. Fraix V, Houeto JL, Lagrange C, Le Pen C, Krystkowiak $\mathrm{P}$, Guehl D, et al. Clinical and economic results of bilateral subthalamic nucleus stimulation in Parkinson's disease. J Neurol Neurosurg Psychiatry 2006; 77: 443-449. DOI:10.1136/jnnp.2005.077677

43. Lanotte M, Rizzone M, Bergamasco B, Faccani G, Melcarne A, Lopiano L. Deep brain stimulation of the subthalamic nucleus: anatomical, neurophysiological, and outcome correlations with the effects of stimulation. J Neurol Neurosurg Psychiatry 2002; 72: 53-58. PMID:11784826

44. Jiang C, Li L, Hao H. Carbon nanotube yarns for deep brain stimulation electrode. IEEE Trans Neural Syst Rehabil Eng 2011; 19: 612-616. PMID:21859605

45. Comston A, Coles A. Multiple sclerosis. Lancet 2002; 359: 1221-1231. DOI:10.1016/S0140-6736(08)61620-7

46. Cellot G, Cilia E, Cipollone S, Rancic V, Sucapane A, Giordani S, et al. Carbon nanotubes might improve neuronal performance by favouring electrical shortcuts. Nat Nanotech 2009; 4: 126-133. DOI:10.1038/nnano.2008.374

47. Hassanzadeh P, Arbabi E, Atyabi F, Dinarvand R. Ferulic acid exhibits antiepileptogenic effect and prevents oxidative stress and cognitive impairment in the kindling model of epilepsy. Life Sci 2016 doi: 10.1016/j.1fs.2016.08.011 [Epub ahead of print].

48. Fisher RS, Ho J. Potential new methods for antiepileptic drug delivery. CNS Drugs 2002; 16: 579-593. PMID:12153331

49. Schwab ME. Repairing the injured spinal cord. Science 2002; 295: 1029-1031. PMID:11834824

50. Sahni V, Kessler JA. Stem cell therapies for spinal cord injury. Nat Rev Neurol 2010; 6: 363-372. DOI:10.1038/ nrneurol.2010.73

51. Roman JA, Niedzielko TL, Haddon RC, Parpura V, Floyd CL. Single-walled carbon nanotubes chemically functionalized with polyethylene glycol promote tissue repair in a rat model of spinal cord injury. J Neurotrauma 2011; 28: 2349-2362. DOI: 10.1089/neu.2010.1409

52. Kim SU. Genetically engineered human neural stem cells for brain repair in neurological diseases. Brain Dev 2007; 29: 193-201. DOI:10.1016/j.braindev.2006.07.012

53. Huang YJ, Wu HC, Tai NH, Wang TW. Carbon nanotube rope with electrical stimulation promotes the differentiation and maturity of neural stem cells. Small 2012; 8: 2869-2877. DOI:10.1002/smll.201200715

54. Lee HJ, Park J, Yoon OJ, Kim HW, Lee DY, Kim DH, et al. Amine-modified single-walled carbon nanotubes protect neurons from injury in a rat stroke model. Nat Nanotech 2011; 6: 121-125. DOI:10.1038/nnano.2010.281

55. Moon SU, Kim J, Bokara KK, Kim JY, Khang D, Webster TJ, et al. Carbon nanotubes impregnated with subventricular zone neural progenitor cells promotes recovery from stroke. Int J Nanomed 2012; 7: 2751-2765. DOI:10.2147/ IJN.S30273 
56. Al-Jamala KT, Gherardinic L, Bardic G, Nunesa A, Guoa $\mathrm{C}$, Bussya $\mathrm{C}$, et al. Functional motor recovery from brain ischemic insult by carbon nanotube-mediated siRNA silencing. PNAS 2011; 108: 10952-10957. DOI:10.1073/ pnas. 1100930108

57. Lindsay RM. Neurotrophic growth factors and neurodegenerative diseases: therapeutic potential of the neurotrophins and ciliary neurotrophic factor. Neurobiol Aging 1994; 15: 249-251. PMID:7838303

58. Son SJ, Bai X, Nan AJ, Ghandehari H, Lee SB. Template synthesis of multifunctional nanotubes for controlled release. J Control Release 2006; 114: 43-152. DOI:10.1016/j.jconrel.2006.06.004

59. Bhirde AA, Patel V, Gavard J, Zhang G, Sousa AA, Masedunskas A, et al. Targeted killing of cancer cells in vivo and in vitro with EGF-directed carbon nanotube-based drug delivery. ACS Nano 2009; 3: 307-316. DOI:10.1021/ $\mathrm{nn} 800551 \mathrm{~s}$

60. Bokara KK, Kim JY, Lee Y, Yun K, Webster TJ, Jong Eun Lee JE, et al. Biocompatability of carbon nanotubes with stem cells to treat CNS injuries. Anat Cell Biol 2013; 46: 85-92. DOI:10.5115/acb.2013.46.2.85

61. Matsumoto K, Sato C, Naka Y, Kitazawa A, Whitby RL, Shimizu N. Neurite outgrowths of neurons with neurotrophin-coated carbon nanotubes. J Biosci Bioeng 2007; 103: 216-220. DOI:10.1263/jbb.103.216

62. Browne SE, Lin L, Mattsson A, Georgievska B, Isacson O. Selective antibody-induced cholinergic cell and synapse loss produce sustained hippocampal and cortical hypometabolism with correlated cognitive deficits. Exp Neurol 2001; 170: 36-47. DOI:10.1006/exnr.2001.7700

63. Huang F, Wang J, Chen A. Effects of co-grafts mesenchymal stem cells and nerve growth factor suspension in the repair of spinal cord injury. J Huazhong Univ Sci Technolog Med Sci 2006; 26: 206-210. PMID:16850748

64. Lad SP, Neet KE, Mufson EJ. Nerve growth factor: structure, function and therapeutic implications for Alzheimer's disease. Curr Drug Targets CNS Neurol Disord 2003; 2: 315-334. PMID:14529363

65. Chen W, Xiong Q, Ren Q, Guo Y, Li G. Can aminofunctionalized carbon nanotubes carry functional nerve growth factor? Neural Regen Res 2014; 9: 285-292. DOI:10.4103/1673-5374.128225

66. Cho Y, Borgens RB. Electrically controlled release of the nerve growth factor from a collagen-carbon nanotube composite for supporting neuronal growth. JMater Chem
B 2013; 1: 4166-4170. DOI: 10.1039/C3TB20505C

67. Hassanzadeh P, Arbabi E, Atyabi F, Dinarvand R. Nerve growth factor-carbon nanotube complex exerts prolonged protective effects in an in vitro model of ischemic stroke. Life Sci 2016; DOI: 10.1016/j.1fs.2016.11.029

68. Draper HH, Hadley M. Malondialdehyde determination as index of lipid peroxidation. Methods Enzymol 1990; 186: 421-431. PMID:2233309

69. Warner DS, Sheng H, Batinic-Haberle I. Oxidants, antioxidants and the ischemic brain. J Exp Biol 2004; 207: 3221-3231. DOI:10.1242/jeb.01022

70. Fantacci C, Capozzi D, Ferrara P, Chiaretti A. Neuroprotective role of nerve growth factor in hypoxic-ischemic brain injury. Brain Sci 2013; 3: 1013-1022. DOI:10.3390/ brainsci3031013

71. Hassanzadeh P, Arbabi E, Rostami F, Atyabi F, Dinarvand R. Carbon nanotubes prolong the regulatory action of nerve growth factor on the endocannabinoid signaling. Physiol Pharmacol 2015; 19: 167-176. URL: http://phypha.ir/ppj/article-1-1112-en.html

72. Di Marzo V, Melck D, Bisogno T, De Petrocellis L. Endocannabinoids: endogenous cannabinoid receptor ligands with neuroremodulatory action. Trends Neurosci 1998; 21: 521-528. PII: S0166-2236(98)01283-1

73. Ferna'ndez-Ruiz JJ, Berrendero F, Herna'ndez ML, Ramos JA. The endogenous cannabinoid system and brain development. Trends Neurosci 2000; 23: 14-20. PMID: 10631784

74. Wilson RI, Kunos G, Nicoll RA. Presynaptic specificity of endocannabinoid signalling in the hippocampus. Neuron 2001; 31: 453-462. PMID:11516401

75. Boger DL, Sato H, Lerner AE, Hedrick MP, Fecik RA, Miyauchi $\mathrm{H}$, et al. Exceptionally potent inhibitors of fatty acid amide hydrolase: the enzyme responsible for degradation of endogenous oleamide and anandamide. Proc Natl Acad Sci USA 2000; 97: 5044-5049. PMID:10805767

76. Casanova ML, Blazquez C, Martinez-Palacio J, Villanueva C, Fernandez-Acenero MJ, Huffman JW, et al. Inhibition of skin tumor growth and angiogenesis in vivo by activation of cannabinoid receptors. J Clin Invest 2003; 111: 43-50. DOI:10.1172/JCI16116

77. Centonze D, Rossi S, Finazzi-Agrò A, Bernardi G, Maccarrone $\mathrm{M}$. The endocannabinoid system in multiple sclerosis and amyotrophic lateral sclerosis. Int Rev Neurobiol 2007; 82: 171-186. DOI:10.1016/S0074-7742(07)82009-5 
78. Lavie G, Teichner A, Shohami E, Ovadia H, Leker RR. Long term cerebroprotective effects of dexanabinol in a model of focal cerebral ischemia. Brain Res 2001; 901: 195-201. PMID:11368967

79. Van der Stelt M, Mazzola C, Esposito G, Matial I, Petrosino S, De Filippis D, et al. Endocannabinoids and $\beta$-amyloid-induced neurotoxicity in vivo: effect of pharmacological elevation of endocannabinoid levels. Cell Mol Life Sci 2006; 63: 1410-1424. DOI:10.1007/ s00018-006-6037-3

80. Arevalo-Martin A, Garcia-Ovejero D, Sierra-Palomares Y, Paniagua-Torija B, Gonzalez-Gil I, Ortega-Gutierrez $\mathrm{S}$, et al. Early endogenous activation of $\mathrm{CB} 1$ and $\mathrm{CB} 2$ receptors after spinal cord injury is a protective response involved in spontaneous recovery. PLOS one 2012; 7: e49057. DOI:10.1371/journal.pone.0049057

81. Wallace MJ, Martin BR, De Lorenzo RJ. Evidence for a physiological role of endocannabinoids in the modulation of seizure threshold and severity. Eur J Pharmacol 2002; 452: 295-301. PMID: 12359270

82. Hassanzadeh P, Arbabi E, Atyabi F, Dinarvand R. Carbon nanotube-anandamide complex exhibits sustained protective effects in an in vitro model of stroke. Physiol Pharmacol 2016; 20: 12-23. URL: http://phypha.ir/ppj/ article-1-1155-en.html

83. Hassanzadeh P, Arbabi E, Atyabi F, Dinarvand R. Application of carbon nanotubes as the carriers of the cannabinoid, 2-arachidonoylglycerol: Towards a novel treatment strategy in colitis. Life Sci 2016; DOI: 10.1016/j. lfs.2016.11.015 